\title{
Mapping School Segregation: Using GIS to Explore Racial Segregation between Schools and their Corresponding Attendance Areas
}

\author{
Deenesh Sohoni \\ William \& Mary, dssoho@wm.edu \\ Salvatore Saporito \\ William \& Mary, sjsapo@wm.edu
}

Follow this and additional works at: https://scholarworks.wm.edu/aspubs

Part of the Educational Sociology Commons

\section{Recommended Citation}

Sohoni, Deenesh and Saporito, Salvatore, Mapping School Segregation: Using GIS to Explore Racial Segregation between Schools and their Corresponding Attendance Areas (2009). American Journal of Education, 115(4), 569-600.

https://doi.org/10.1086/599782

This Article is brought to you for free and open access by the Arts and Sciences at W\&M ScholarWorks. It has been accepted for inclusion in Arts \& Sciences Articles by an authorized administrator of W\&M ScholarWorks. For more information, please contact scholarworks@wm.edu. 


\title{
Mapping School Segregation: Using GIS to Explore Racial Segregation between Schools and Their Corresponding Attendance Areas
}

\author{
DEENESH SOHONI and SALVATORE SAPORITO \\ College of William and Mary
}

\begin{abstract}
We examine whether student enrollment in nonneighborhood schools changes levels of racial segregation in public schools across urban school districts by comparing the racial composition of schools and their corresponding attendance area. This comparison was made possible by using geographic information systems (GIS) to link maps of elementary, middle, and high school attendance boundaries with 2000 census data, the Common Core of Data, and the Private School Survey for the 22 largest school districts. Results show that public schools would be less racially segregated if all children living in a school district attended their local, neighborhood schools. Similarly, findings reveal that private, magnet, and charter schools contribute to overall racial segregation within most school districts. Finally, while segregation levels in school catchment areas become lower from elementary to middle to high schools, the difference in segregation between catchment areas and the schools that serve them remains constant across all levels.
\end{abstract}

For the past several decades scholars and educational policy makers have debated the extent to which the enrollment of children in private, charter, and magnet schools affects racial segregation in traditional neighborhood public schools. While researchers investigating residential racial segregation consistently find that race influences neighborhood choice (Alba and Logan 1993; Crowder 2000; Emerson et al. 2001; Massey and Denton 1993; Quillian 1999, 2002; South and Crowder 1998), researchers examining racial segregation in public schools continue to debate whether familial choices for schools are racially motivated. Specifically, these scholars seek to understand to what degree family choices regarding schooling contribute to segregation in schools beyond what is expected, given existing residential patterns. This question has significant policy implications given the introduction and expansion of school

Electronically published June 4, 2009

American Journal of Education 115 (August 2009)

(C) 2009 by The University of Chicago. All rights reserved.

0195-6744/2009/11504-0005\$10.00

AUGUST 2009 


\section{Mapping School Segregation}

voucher programs and other "free market" educational reforms that may exacerbate racial segregation.

In one of the earliest statements concerning the impact of private schools on traditional neighborhood public schools, James Coleman and his colleagues argued that private school enrollment does "not increase the level of segregation beyond that which statistical evidence indicates would exist in the public sector if private schools were absent" (Coleman et al. 1982b, 220). More recently, "school choice" advocates have argued that more important for families than the racial composition of schools are their programs and pedagogical characteristics (Merrifield 2001, 136) and that increasing choice programs may even serve to facilitate traditional social policy objectives such as racial integration (Finn 1990, 7). By contrast, other scholars contend that allowing greater mobility will exacerbate racial segregation. These scholars theorize that white and wealthier students will seek to maintain their social status by distancing themselves from groups they perceive to be of lower standing (Taeuber and James 1982, 1983; Wells and Crain 1992). A number of researchers make this argument in their assessment of various choice policies (Henig 1996; Lankford and Wyckhoff 2001, 2006; Saporito 2003; Wrinkle et al. 1999). From this view, broadening the educational options of students will merely add another layer of stratification to an educational system already differentiated by race and class (Astin 1992).

Even though many scholars have debated the merits of Coleman's hypothesis that increasing choice in private schools does not impact racial segregation in public schools, only recently has it been tested directly with empirical evidence (Saporito and Sohoni 2006, 2007). The research shows that public schools in the largest U.S. school districts would be less racially segregated if all children living in their school districts attended neighborhood schools and that, with only a few exceptions, the presence of private, magnet, and charter schools contributes to overall racial segregation for urban school districts. The limitation with this research is that it does not disaggregate

DeEnesh Sohoni, PhD, is associate professor, Department of Sociology, College of William and Mary. His main fields of research are the sociology of education, racial and economic segregation, and the social incorporation of immigrant groups. His current research examines media representations of immigrants and immigration to the United States. Salvatore SaPorito, $\mathrm{PhD}$, is associate professor, Department of Sociology, College of William and Mary. His main fields of interest are the sociology of education, stratification, racial and economic segregation, human geography, and areal interpolation methods. His current research explores private school enrollment rates by student race and the racial composition of communities between 1970 and 2007. 


\section{Sohoni and Saporito}

schools by level (i.e., elementary, middle, and high schools). Mixing schools of different levels into a single analysis (or observing only one level at a time) may overlook or obscure the effects of magnet schooling (and other choice programs) on segregation within school districts. We therefore refine and extend earlier work incorporating data at the elementary, middle, and high school levels by analyzing them separately.

There are several theoretical reasons to examine and compare racial segregation across multiple school levels. As scholars on residential segregation have noted, the size of geographic units may be related to the degree of segregation between units. In our case, the larger the size of the school attendance boundaries within a school district, the more likely it is that such units are racially heterogeneous. With respect to public schools, the geographic regions covered by school catchment areas typically grow larger as students move up the grade ladder from elementary to middle to high schools. Thus, unless school boundaries are "racially gerrymandered," we would expect to find increasingly lower levels of racial segregation among children in high school catchment areas than in middle and elementary school catchment areas.

It is also possible, however, that expected increases in racial integration in higher grades due to the expansion of school catchment areas may be counteracted by white families being more apt to enroll their children in nonneighborhood schools in an effort to avoid contact with nonwhite children. Indeed, Saporito and Sohoni (2006) found that the closer a school catchment area was to a 50/50 split between the percentage of children who were white and nonwhite, the greater the difference there was between the percentage of white children in a school and its corresponding catchment area. Specifically, there were fewer (by nearly 10 percentage points) white children in elementary schools than in their corresponding catchment areas when roughly 50 percent of the children in a catchment area were nonwhite. Given that more middle and high schools than elementary schools approach the 50/50 white/nonwhite split, greater percentages of older children may attend nonneighborhood schools to avoid integration in local, public schools. In short, it may be the case that there is greater racial integration in middle and high school catchment areas than there is in elementary school catchment areas. However, the difference in racial segregation between schools and their catchment areas may be greater for higher grades than for lower grades, an issue specifically examined in this article.

To answer these questions, we use geographic information system technology (GIS) to examine levels of racial segregation across school levels in public schools. Specifically, we examine the effects of student choices on school segregation by using residential segregation as a baseline against which we compare rates of school segregation. Using GIS, we are able to create a unique data set that allows us to address three key questions regarding racial segre-

AUGUST 2009 


\section{Mapping School Segregation}

gation in schools, school choice, and desegregation policies. First, How does racial segregation differ between public neighborhood schools and the catchment areas they serve? This allows us to address Coleman's claim that the shift of children from neighborhood to private schools has no impact on racial segregation in public schools. Second, How does racial segregation of students across all schools within a district compare with racial segregation of schoolaged children living in school catchment areas? This lets us assess how much the redistribution of some students from neighborhood schools to private, magnet, and charter schools affects overall racial segregation within a district. Finally, Do the school choices of older children have a greater impact on racial segregation than they do among elementary school-aged children?

Data and Method

In order to assess how private, charter, and magnet schools affect the racial composition of local neighborhood pubic schools, it is necessary to determine what the racial composition of public schools would be if every child attended his or her assigned neighborhood school. To do this, we collected maps describing school attendance boundaries for the largest school districts in the country. ${ }^{1}$ These maps came in a variety of formats. Some school districts provided maps in GIS form (typically as a shape file), while other districts provided boundary information on paper. We converted these paper maps into digital GIS files through the process of digitizing (i.e., creating digital images of paper maps).

The process of digitizing paper maps of school attendance boundaries entailed several interrelated steps. First, we created a digital image of paper maps depicting school attendance boundary maps; this was accomplished by scanning these paper maps to create digital images. Specifically, we created TIFF (tagged image file format) files. Digital images of the paper maps were then imported into GIS software. In the next step, we georeferenced these digital images to GIS data such as streets, railroads, and other line features available on the Internet. Georeferencing is the process of aligning an image file (in this case, an image of school attendance boundaries that are depicted alongside streets, railways, and waterways) with spatially referenced data. For this project, we georeferenced paper maps of school attendance boundaries with the Census Bureau's TIGER line files of streets, railways, waterways, and other related features. The process of georeferencing digital images of school attendance boundaries to TIGER files essentially requires assigning geographically referenced control points (i.e., latitude and longitude) to several points in the image of school attendance boundaries that correspond with the same points in TIGER files. For example, we georeferenced street intersections of our TIFF

\section{American Journal of Education}




\section{Sohoni and Saporito}

images with the corresponding spatially reference street intersections in the TIGER files. (Digital shape files of all U.S. streets are available on the Internet for free.) If completed properly, georeferencing allows a user to overlay digitally scanned paper maps on top of preexisting digital files such as streets and so forth. ${ }^{2}$ Some people call the process of georeferencing "rubber sheeting" because it allows users to stretch and contort images of maps so that they correspond with spatially referenced GIS maps. Georeferencing images of paper maps makes the process of "on screen" digitizing fairly straightforward. In the example of school boundaries, a user can create polygons of enrollment zones by tracing along the (geographically referenced) digital image of school attendance boundaries.

The 22 school districts for which we collected maps represented less than .2 percent of the total number of school districts in the United States. Still, these districts contained 12 percent of all children enrolled in school, and, significant for this study, these school districts are racially diverse. As seen in table 1, the percentage of white students living within the 22 school districts included in this study ranges from 5.3 to 72.5 , the percentage of black students ranges from 9.5 to 86.0, and the percentage of Hispanic students ranges from 1.5 to 64.2 percent of the total. In addition, the students enrolled in private school range from 7.9 to 23.2 percent. Furthermore, in some districts, such as those in Chicago and Philadelphia, over half of all white students attend private schools, while in Clark County, Nevada, only 11 percent do. This variation in racial composition and private school attendance in the largest U.S. school districts allows us to explore the dynamics of racial segregation across diverse settings.

Integrating School Attendance Boundaries with 2000 Census Data

Once we created GIS-based school attendance boundary maps, we integrated them with block-level data from the Census Bureau. This was done by overlaying the digital maps of school catchment areas on top of maps of census blocks. These overlays allowed us to identify the school that served every block in each school district. Because the 2000 census data identify all persons by age and race at the block level, we were able to determine the number of children by race who lived in each school catchment area. Using this information, we tabulated the number of children in each school catchment area (for all school levels) who were white, non-Hispanic, black, and Hispanic. These racial tabulations established a baseline level of racial segregation in school neighborhoods. As suggested in the debates between Coleman and his colleagues (1982a, 1982b, 1983) and Taeuber and James (1982, 1983), our baseline measure represents a hypothetical level of racial segregation across 


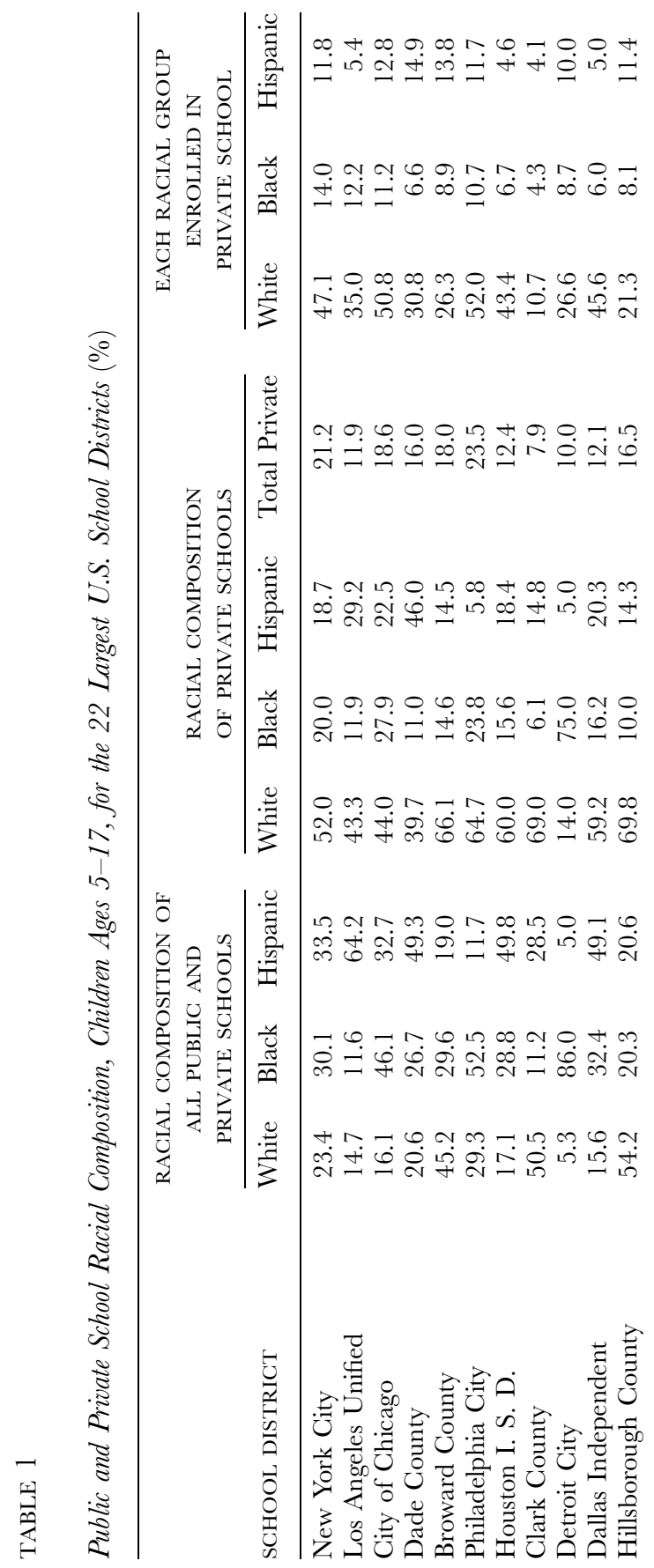

574

This content downloaded from 128.239.241.216 on December 06, 2018 08:11:08 AM 


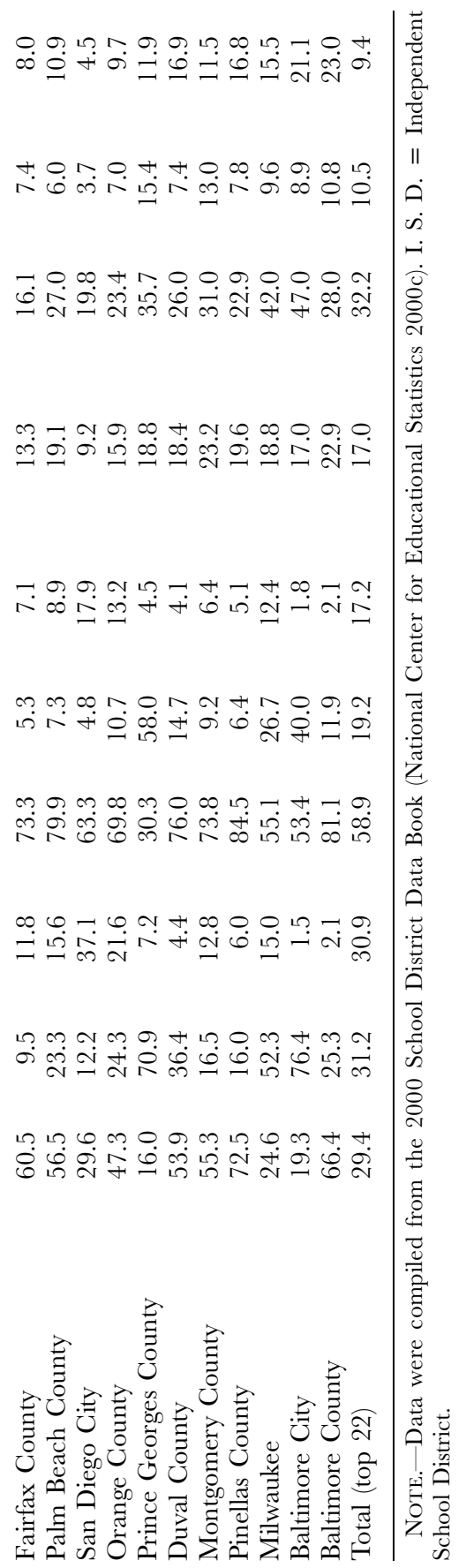

575

This content downloaded from 128.239.241.216 on December 06, 2018 08:11:08 AM 


\section{Mapping School Segregation}

schools within a district, assuming that all students attend the local public schools serving their neighborhoods. ${ }^{3}$ For example, if 30 percent of the children in a school attendance boundary are white (i.e., the baseline measure) then one would expect that 30 percent of the children who are enrolled in the local public school would be white.

Integrating Census Counts of School Attendance Boundaries with the Common Core of Data

Our next step was to link these maps with information describing the racial composition of the schools that actually serve these attendance boundaries. We did this by using information from the Common Core of Data (CCD), available from the U.S. Department of Education's National Center for Educational Statistics (2000a, 2000b, 2000c). The 1999-2000 and 2000-2001 CCD describe the number of children by grade level and race for virtually every public school (including charter and magnet schools) in the country. This enables us to link all school attendance boundaries with the actual school information provided in the GCD.

The grade-level organization of the schools we examined did not correspond neatly with the Census Bureau's Summary Files 1 (SFl) block-level age categories. Age categories for $\mathrm{SF} 1$ block-level census data divide children into ages 5-9, 10-14, and 15-17 (U.S. Bureau of the Census 2003). We use these ranges to represent elementary-, middle-, and high-school-aged children. To be sure, these age categories are not a perfect representation of the grade structure in the typical elementary, middle, or high school. Still, the slight discrepancy between grades and ages has virtually no bearing upon the results, because the racial percentages across ages are nearly identical within school districts.

Fortunately, the GCD provides enrollment data by grade level and race. We define elementary schools as consisting of grades $1-4$, middle schools as grades 7-8, and high schools as grades $9-10$. Using grades $1-4$ allows us to closely match the age 5-9 category in the 2000 census while maintaining consistency in the grade structure across schools. In this study, middle schools consist of grades 7-8. We use only grades $9-10$ to represent high school. This allows us to reduce the potential bias that may be introduced by differences in dropout rates between white and nonwhite students in higher grade levels. Still, any bias would likely be conservative, as we expect the differential dropout rates between white and nonwhite students to create higher rates of white children in a school compared with the catchment area. Given that we hypothesize that there will be lower rates of white children in a school compared with its catchment area, dropout rates represent a condition that likely undermines our hypothesis (at the high school level). ${ }^{4}$ In addition to neighbor- 


\section{Sohoni and Saporito}

hood-based schools, the CCD also contained schools that did not serve a specific attendance area but, in fact, served children from across the entire school district. As shown in tables 2 and 3, these were either whole-dedicated magnet or charter schools.

After linking the census-based school catchment data with the CGD, we constructed racial variables for both data sets. Although the census's blocklevel data and the CCD are both based on population counts, their racial classification systems differ slightly. Fortunately, both data sets count the number of whites who are not Hispanic and, in this respect, the two data sets are comparable (for simplicity, we refer to children who are white, non-Hispanic as "white"). ${ }^{5}$

Data on Private Schools

With the exception of Clotfelter (2004) and Reardon and Yun (2002), most studies of school segregation rely exclusively on public school enrollment information derived from the CCD. To overcome this shortcoming in the existing research, we locate private schools within schools districts; this allows us to explore racial segregation across public and private schools simultaneously. We use data from the 1999 Private School Survey (hereafter called the PSS) that contain information on virtually every private school in the country, including their addresses, racial enrollments, and the number of students in each grade. The availability of private school addresses allowed us to use the address-matching features in GIS to pinpoint the location of every private school.

We located 2,853 private elementary schools, 2,195 private middle schools, and 913 private high schools within the 22 largest school districts in the country (see tables 2, 3, and 4). Locating schools within districts was accomplished by using the geocoding function in GIS, which allowed us to match the street addresses of all schools (that are available in the PSS) with existing street shape files from the U.S. Census Bureau. Once the street addresses for each school were matched to existing street files, they were assigned latitude-longitude coordinates that allowed us to locate each school within a district.

While our data are unique, there is no question that we would have preferred to include variables in our analyses that capture nonracial factors that could account for the percentage of white children who are enrolled in a given school. This would include other neighborhood characteristics that capture socioeconomic factors and school quality measures such as test scores, rates of suspensions or violence, indicators of principal leadership, faculty collegiality, teaching innovation, time on task, or other measures discussed in the literature on school effectiveness (Hallinger and Murphy 1985; Purkey and Smith 1983).

AUGUST 2009 


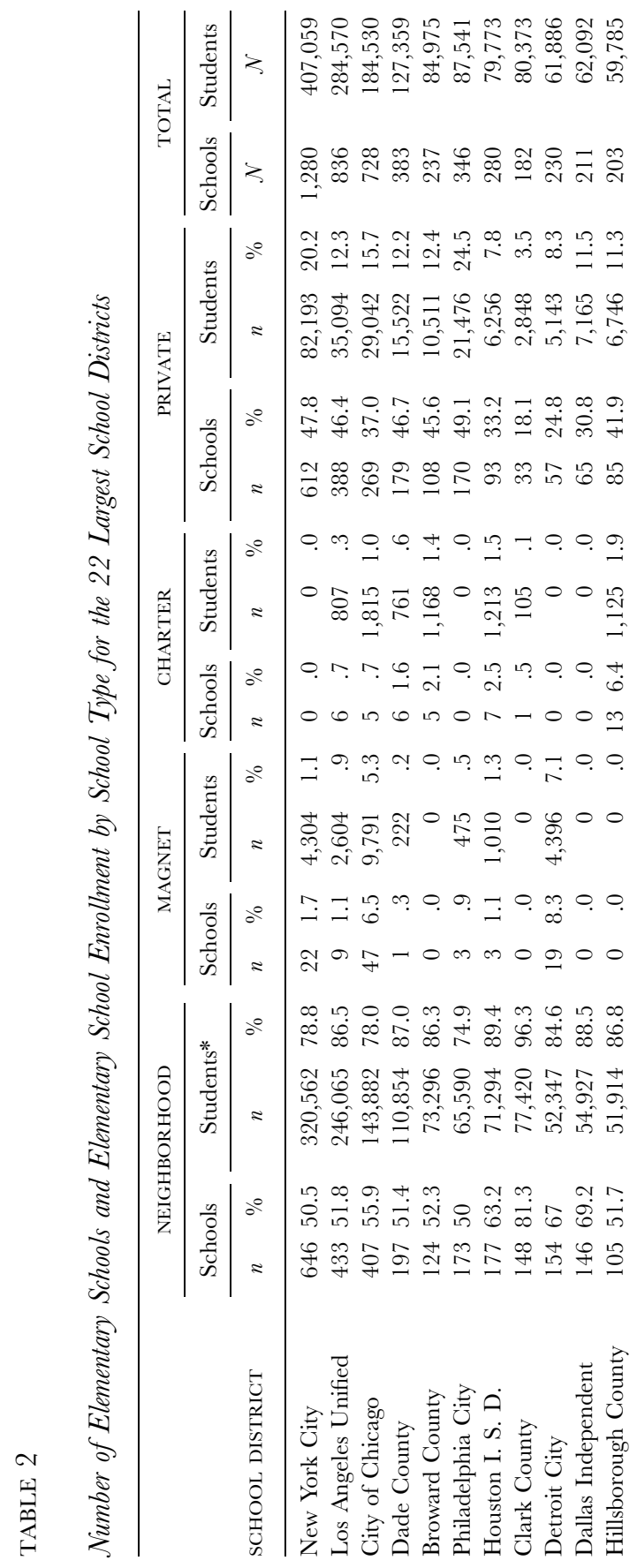

578

This content downloaded from 128.239.241.216 on December 06, 2018 08:11:08 AM 


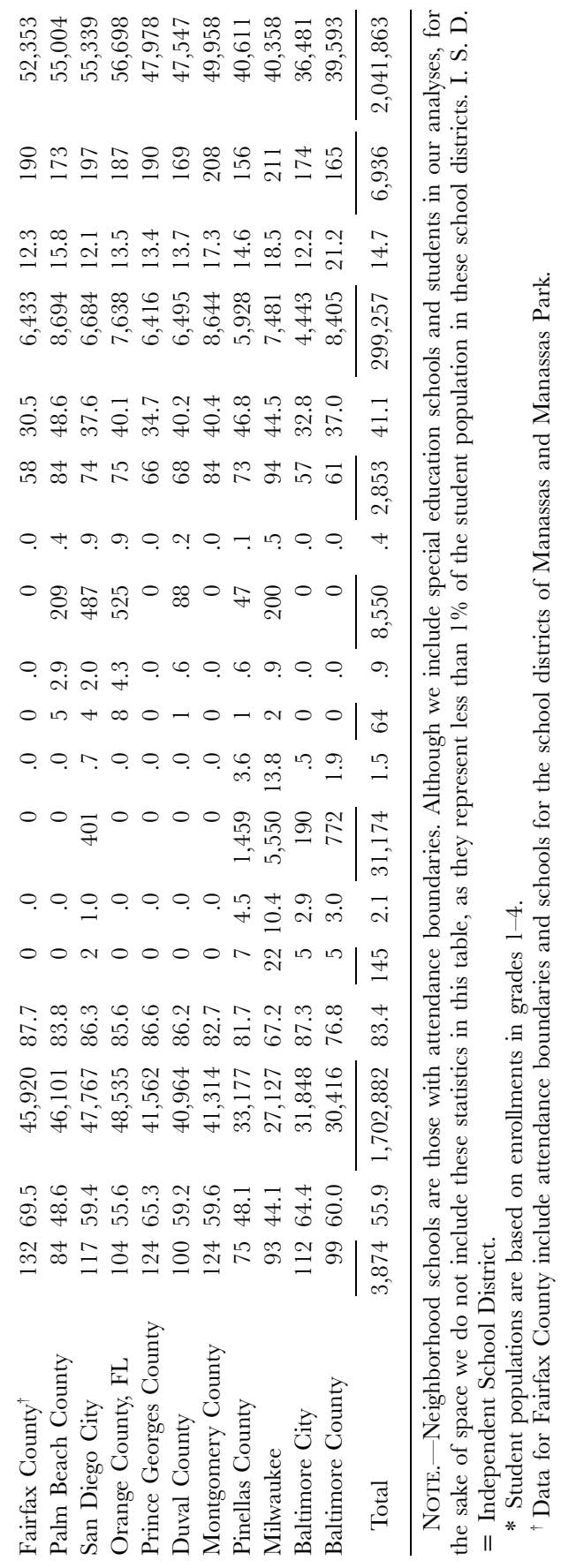




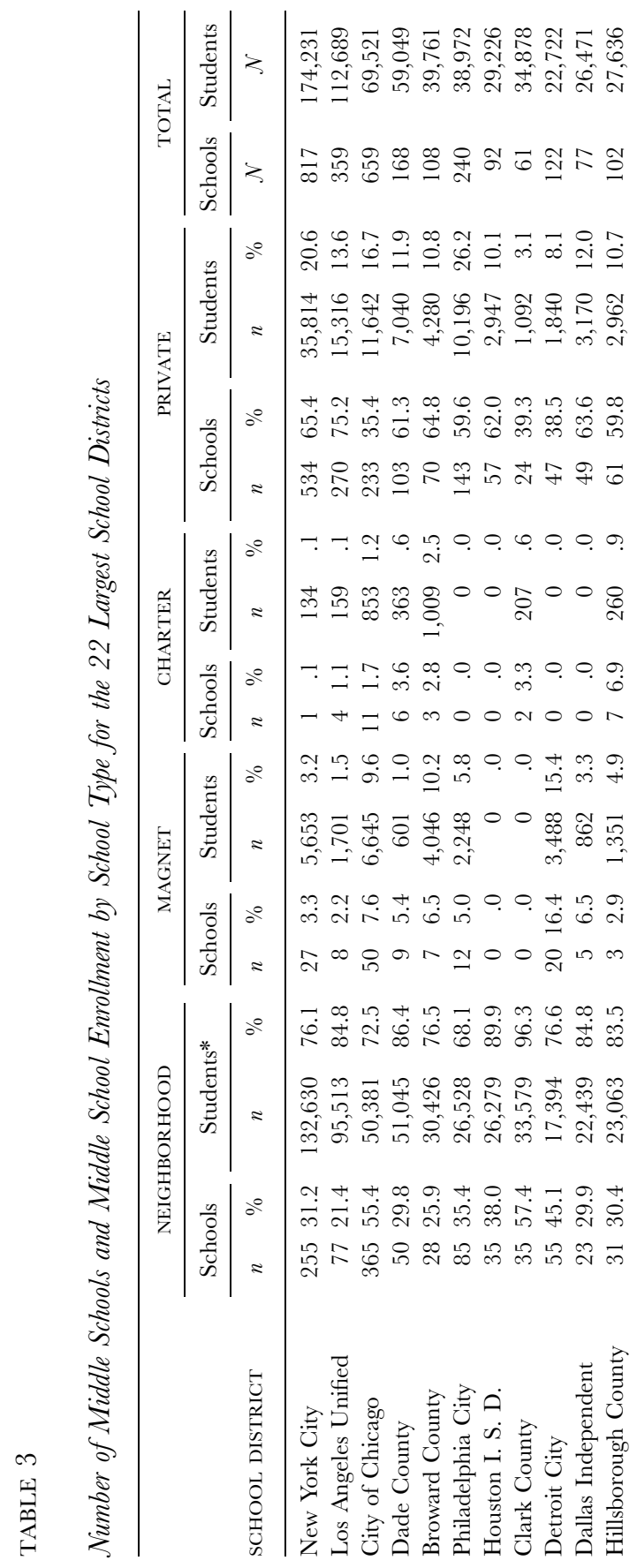

580

This content downloaded from 128.239.241.216 on December 06, 2018 08:11:08 AM 


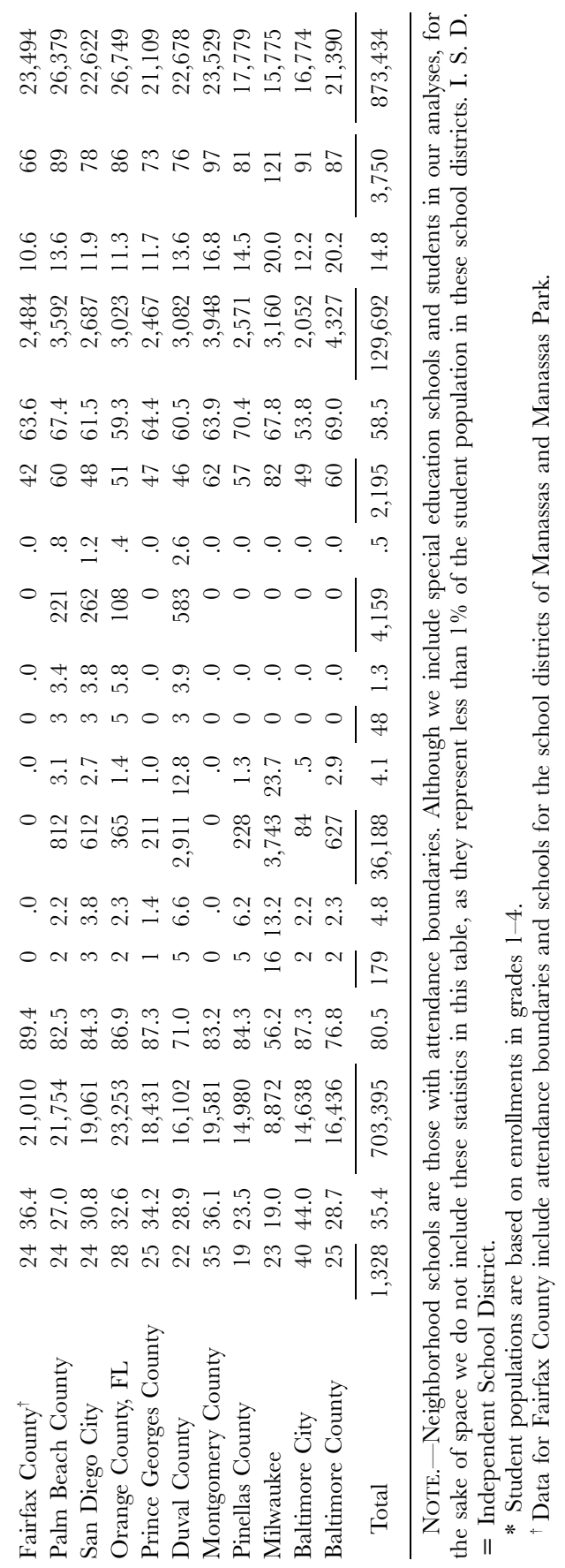

581

This content downloaded from 128.239.241.216 on December 06, 2018 08:11:08 AM 


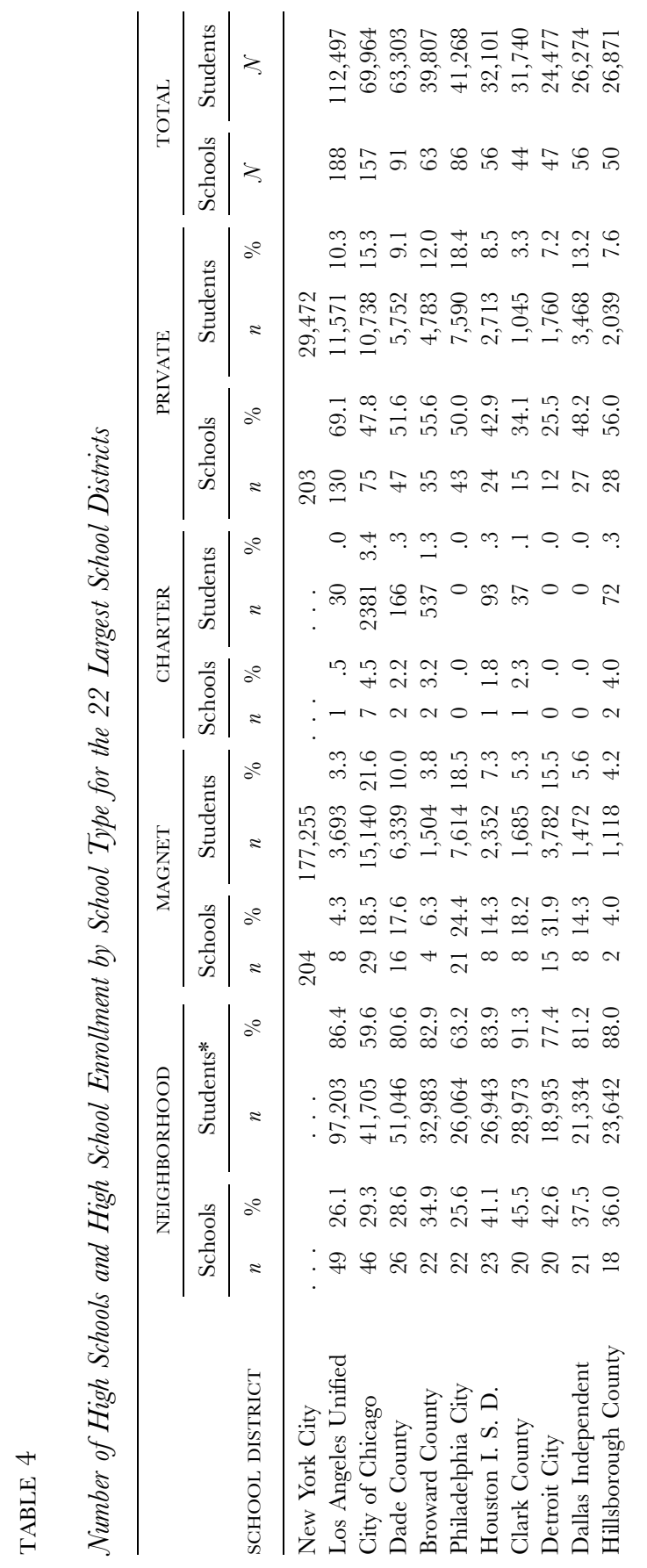

582

This content downloaded from 128.239.241.216 on December 06, 2018 08:11:08 AM 


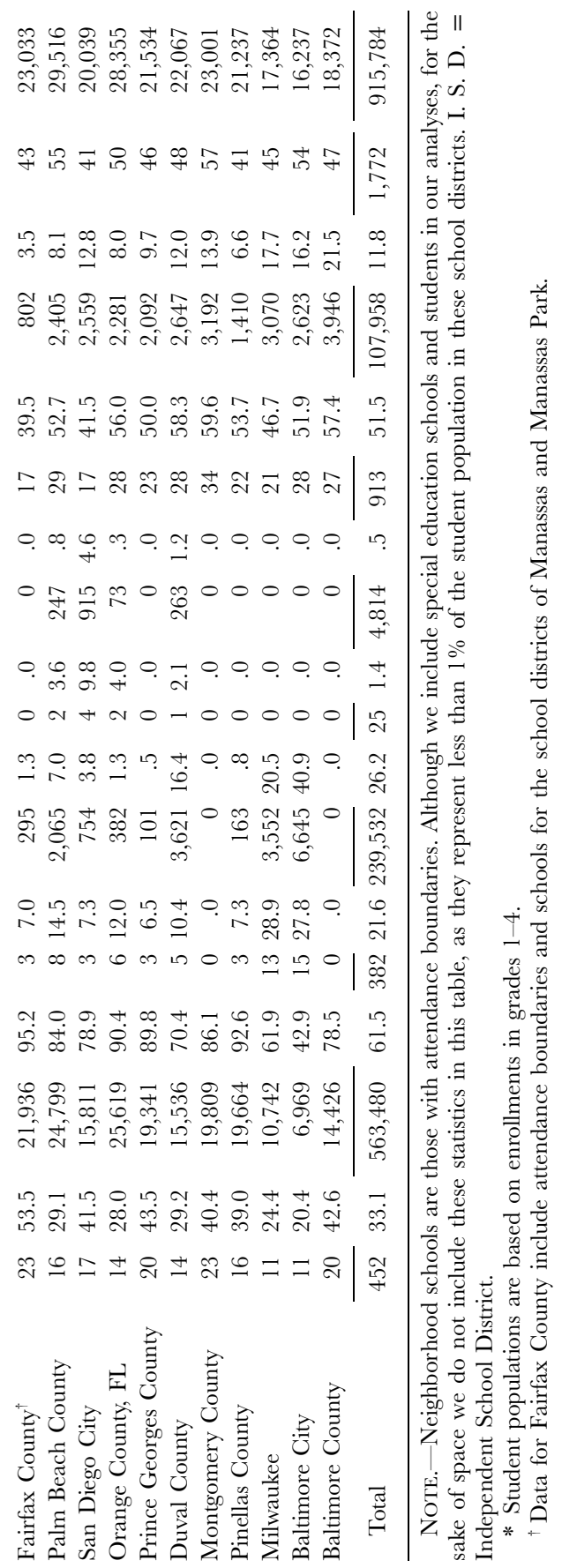

583

This content downloaded from 128.239.241.216 on December 06, 2018 08:11:08 AM 


\section{Mapping School Segregation}

Our inability to include these variables limits our ability to make causal inferences about why white students may be underrepresented in public schools. Nonetheless, documenting the fact that student mobility across neighborhood, private, magnet, and charter schools exacerbates segregation speaks to important debates regarding the link between school choice and segregation.

\section{Analyses and Findings}

For this study, we conduct three interrelated analyses. First, we create a series of simple scatter plots that allows us to visually compare the percentage of white students enrolled in traditional public schools with the percentage of white students living in each school's catchment area. Second, regression models are presented that show the strength of the relation between school catchment area and school racial composition. These models allow us to determine how much the underrepresentation of white children in schools is due to the presence of black and Hispanic children in school catchment areas. Third, within each school district we calculate levels of racial segregation of children living in school attendance areas and compare this with levels of racial segregation in their corresponding schools. These analyses allow us to observe, for each district, how much racial segregation in schools is greater than in their corresponding catchment areas.

\section{Comparing Racial Enrollment in Schools and Their}

Attendance Boundaries

If all children residing in school catchment areas attended their local neighborhood schools, then the racial composition of schools and their neighborhoods would be identical. It is also true that if equal proportions of white, black, and Hispanic children within specific school attendance boundaries attended private, magnet, and charter schools, then the racial mix of students within a traditional neighborhood school would also be the same. Indeed, Coleman et al. (1982a) make this latter claim.

Contrary to these expectations, we find lower percentages of white students in public schools than in their school attendance boundaries. In figures 1, 2, and 3, we show scatter plots depicting the percentage of white students in schools and their corresponding attendance boundaries. We create a hypothetical regression line that runs along a perfect diagonal. This reference line shows the proportion of white students who would be enrolled in traditional neighborhood schools if all students attended their neighborhood school (or

\section{American Journal of Education}




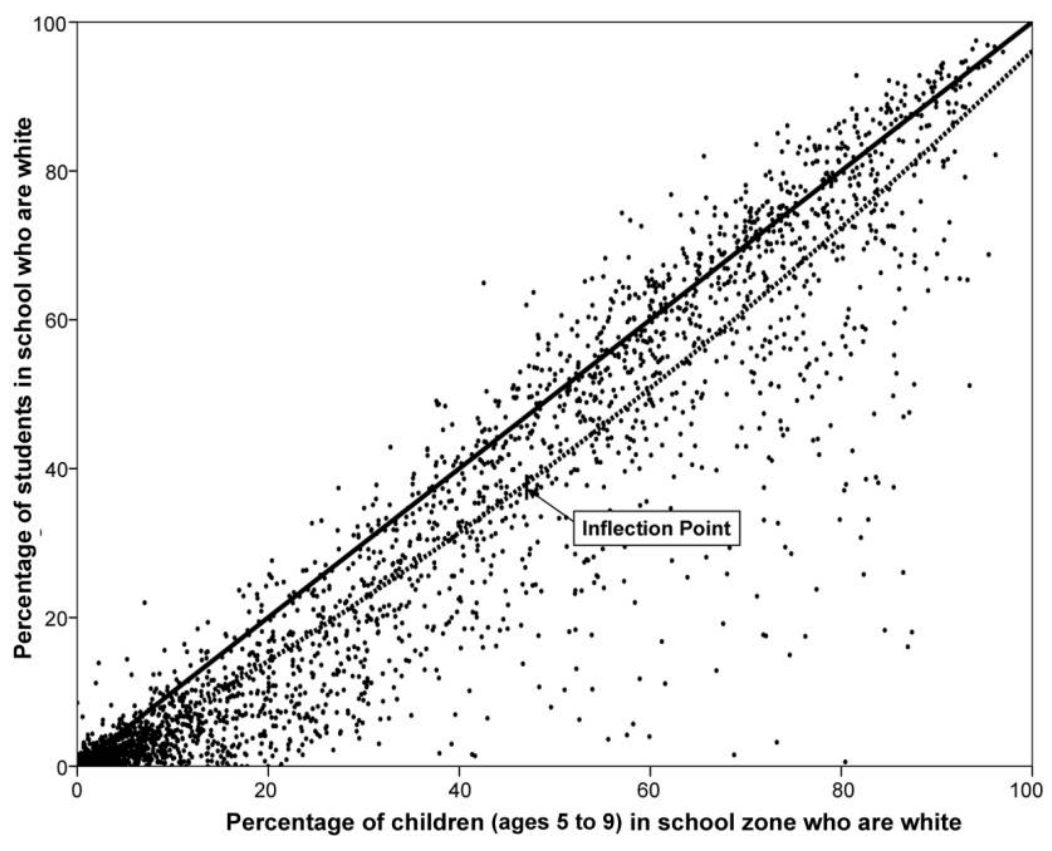

FIG. 1

if white and nonwhite children attended nonneighborhood schools in the same proportions).

When we compare the actual regression lines (i.e., the solid line in figures 1,2 , and 3) with the hypothetical reference lines, two distinct patterns emerge. ${ }^{6}$ First, the average percentage of white students enrolled in schools is lower than the hypothetical regression line. The difference between the percentage of children who are white in schools and their corresponding attendance boundaries is 5 percentage points at the elementary school level and 6 percentage points at the middle and high school levels. This difference is due to white children attending schools of choice (i.e., private, magnet, and charter schools) at higher rates than nonwhite children.

The second pattern we find is the curvilinear relationship between schools and their neighborhoods. The curvilinear regression line shows that the difference between the percentage of white children in schools and their catchment areas is greatest in areas that have roughly equal proportions of white and nonwhite students. Indeed, for elementary schools, the point on the $x$ axis at which the curve is the furthest from the expected regression line (i.e., the inflection point) is 45 percent. $^{7}$ At the inflection point, there are, on average, fewer (by 9 percentage points) white children enrolled in schools than 


\section{Mapping School Segregation}

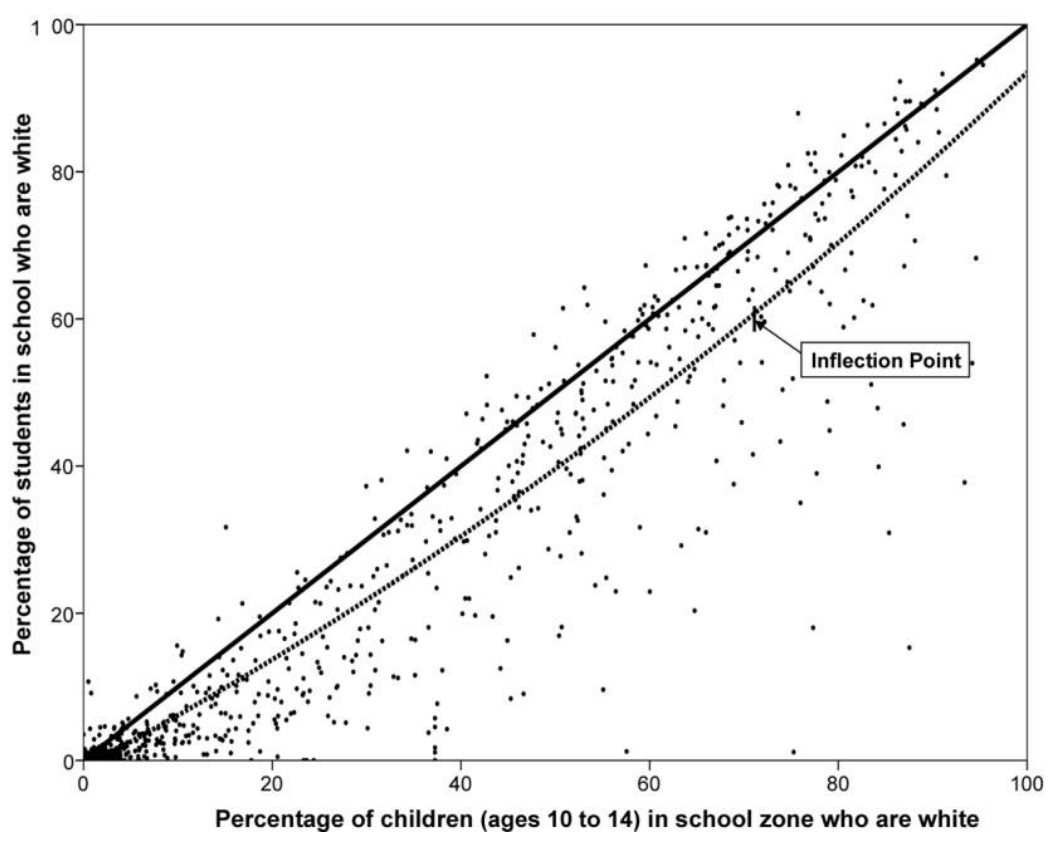

FIG. 2

live in their corresponding catchment areas. For middle schools the inflection point is 70 , and the difference between the observed and expected regression lines is 13. For high schools, the respective numbers are 46 and 10. Thus, where we would expect schools to contain nearly equal proportions of white and nonwhite students is precisely where white children are the most underrepresented in schools relative to their neighborhoods.

Regression Analysis of School Racial Composition

The above analyses show that the percentage of white children enrolled in neighborhood schools is lower than the percentage of white children living in their corresponding neighborhoods. We explore this relationship further by determining whether these differences are affected by the racial composition of the school attendance zones; specifically, we use regression as an analytical tool that can reveal whether the percentage of black children in an attendance zone has a stronger or weaker association with the percentage of white children in a school than does the percentage of Hispanic students in the area. Regression results are shown in table 5 .

\section{6 \\ American Journal of Education}




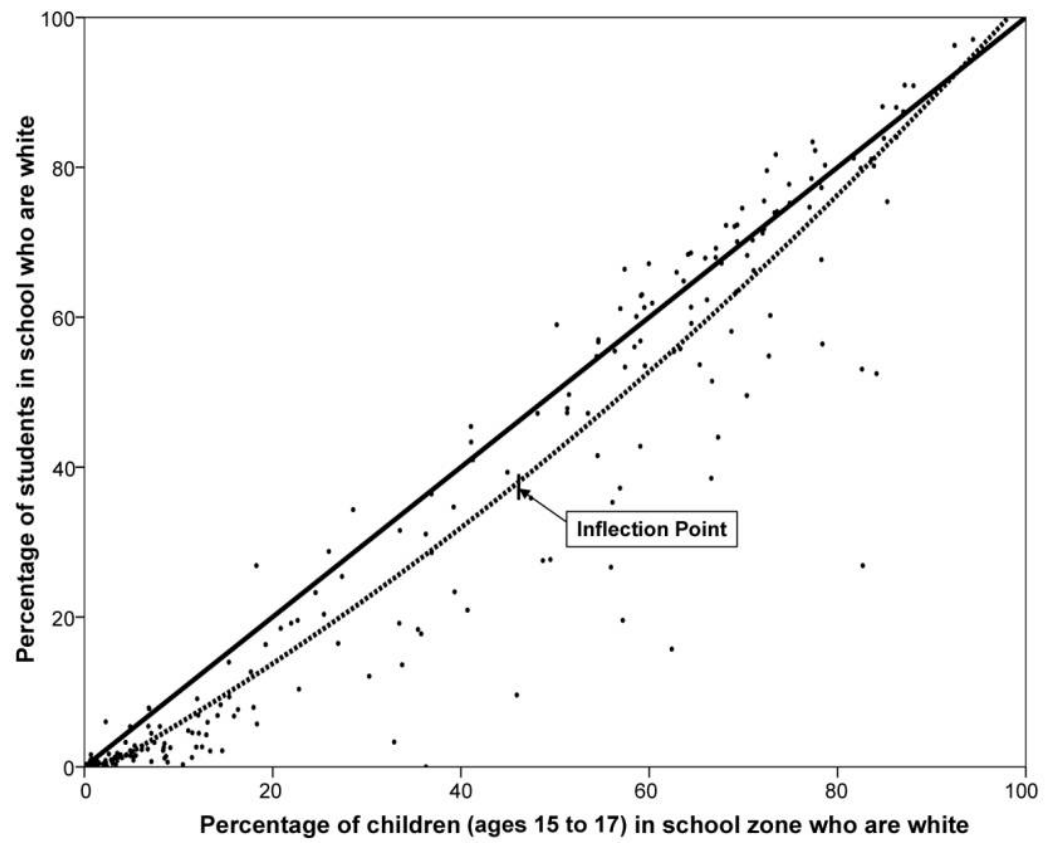

FIG. 3

Model 1 for elementary, middle, and high schools presents the basic relationship between the percentage of white children in schools given two variables: the percentage of white children in a catchment area and the square of this variable to capture the curvilinear nature of this relationship. Explained variance for the model is .884 for elementary schools, .853 for middle schools, and .880 for high schools, suggesting (as one would expect) that racial populations in schools are determined primarily by the racial composition of their attendance boundaries.

A noteworthy finding is the contributions of the quadratic terms in predicting the proportion of children in a school who are white. The standardized regression coefficients range from .191 for elementary schools, increase slightly to .208 for middle schools, and then jump to .305 for high schools. This is important for two reasons: first, the coefficients demonstrate the relatively strong curvilinear relationship between the proportion of children in schools and neighborhoods that are white. Second, the strength of this relationship increases as children move up in school level. This is consistent with our conjecture that as students move into higher school levels, and as school boundaries become more racially balanced, the discrepancy between the percentage of white children in catchment areas and the schools that serve them

AUGUST 2009 


\section{Mapping School Segregation}

TABLE 5

Regression of the Percentage of Student Who Are White in Neighborhood Public Schools by the Characteristics of School Catchment Areas

\begin{tabular}{|c|c|c|c|c|c|c|}
\hline \multirow{2}{*}{$\begin{array}{l}\text { CATCHMENT AREA } \\
\text { CHARACTERISTIC }\end{array}$} & \multicolumn{3}{|c|}{ MODEL 1} & \multicolumn{3}{|c|}{ MODEL 2} \\
\hline & $b$ & $\mathrm{SE} b$ & $\beta$ & $b$ & $\mathrm{SE} b$ & $\beta$ \\
\hline \multicolumn{7}{|l|}{ Elementary schools: } \\
\hline White $(\%)$ & .725 & .019 & .755 & .676 & .031 & .705 \\
\hline White $(\%)$ squared & .002 & .0001 & .191 & .002 & .0001 & .199 \\
\hline Hispanic $(\%)$ & & & & -.046 & .017 & -.050 \\
\hline Black (\%) & & & & -.032 & .017 & -.039 \\
\hline Constant & -.985 & .247 & & 2.786 & 1.660 & \\
\hline$R^{2}$ & .884 & & & .885 & & \\
\hline \multicolumn{7}{|l|}{ Middle schools: } \\
\hline White (\%) & .565 & .034 & .723 & .553 & .059 & .609 \\
\hline White $(\%)$ squared & .002 & .0001 & .208 & .003 & .0001 & .230 \\
\hline Hispanic $(\%)$ & & & & -.084 & .034 & -.091 \\
\hline Black $(\%)$ & & & & -.075 & .034 & -.107 \\
\hline Constant & -.581 & .425 & & 7.202 & 3.389 & \\
\hline$R^{2}$ & .853 & & & .854 & & \\
\hline \multicolumn{7}{|l|}{ High schools: } \\
\hline White $(\%)$ & .649 & .061 & .641 & .491 & .112 & .485 \\
\hline White $(\%)$ squared & .004 & .0001 & .305 & .004 & .001 & .329 \\
\hline Hispanic $(\%)$ & & & & -.134 & .075 & -.121 \\
\hline Black $(\%)$ & & & & -.121 & .071 & -.137 \\
\hline Constant & -1.010 & .924 & & 11.463 & 7.214 & \\
\hline$R^{2}$ & .880 & & & .881 & & \\
\hline
\end{tabular}

NOTE.- Although we show the standard errors, we opt not to present significance levels. Our data consist of the population of neighborhood schools for the 22 largest school districts in the United States.

will grow. Indeed, the coefficients are consistent with the scatter plots in figure 1 that show fewer white students in public schools serving the most racially balanced neighborhoods.

This finding raises an important question: Does the presence of black children and Hispanic children in a catchment area play an equal role in determining the proportion of white children who remain in local, public schools? To answer this question, we compare the relative impact of the presence of black versus Hispanic children in a neighborhood on the percentage of white children in schools, as shown in model $2 .^{8}$ We find that the proportion of children in a catchment area that are black and the proportion that are Hispanic have virtually the same effect on the proportion of students in a school that are white. These coefficients demonstrate the need to pay due

\section{American Journal of Education}




\section{Sohoni and Saporito}

attention to the presence of Hispanic students as well as black students when examining racial segregation in large, urban schools districts.

\section{District-Level Comparisons: Segregation in Schools and Their Attendance} Boundaries

To this point in our analyses, we have described general trends in school enrollment by race for each set of grade levels included in our data as a group. We now shift focus by asking, How does segregation between whites and nonwhites vary across school districts? To answer this question, we use the Dissimilarity Index (or $D$ ) to assess the degree to which racial groups are distributed evenly across schools and school attendance boundaries within a school district. If two racial groups were distributed evenly, each school within a district would have the same racial balance as the entire school district. Dissimilarity values range from zero to one with a value of zero reflecting perfect integration and a value of one reflecting complete segregation. The value of $D$ can be interpreted as the proportion of students from a single racial group that would have to enroll in a different school in order for each school within a district to reflect the racial composition of the entire district. The formula for $D$ is

$$
D=\frac{\sum_{i=1}^{n}\left[t_{i}\left|\left(p_{i}-P\right)\right|\right]}{[2 T P(1-P)]},
$$

where $t_{i}$ is the total population in school $i$ (and $T$ is the total population in all schools). In these analyses, the value of $\mathcal{T}$ should be interpreted as the sum of the two racial groups under comparison. Similarly, $p_{i}$ is the proportion of school $i$ that is of a given racial group, and $P$ is the proportion of a given racial group in all schools within a district.

Dissimilarity is considered the "workhorse" of segregation measures. Although it is used widely because it is interpreted easily, our use of $D$ is driven by its suitability for our research question. We argue that greater levels of segregation in schools than school catchment areas result from the disproportionate loss of white students from schools that serve racially balanced neighborhoods. Dissimilarity captures the evenness with which racial groups are distributed across schools, and thus $D$ captures differences in segregation between schools and their catchment areas that result directly from the uneven loss of white students from integrated school attendance zones. In tables 6 , 7 , and 8 , we show how much the disproportionate loss of white students from schools serving more heterogeneous areas impacts segregation in the 22 largest

AUGUST 2009 


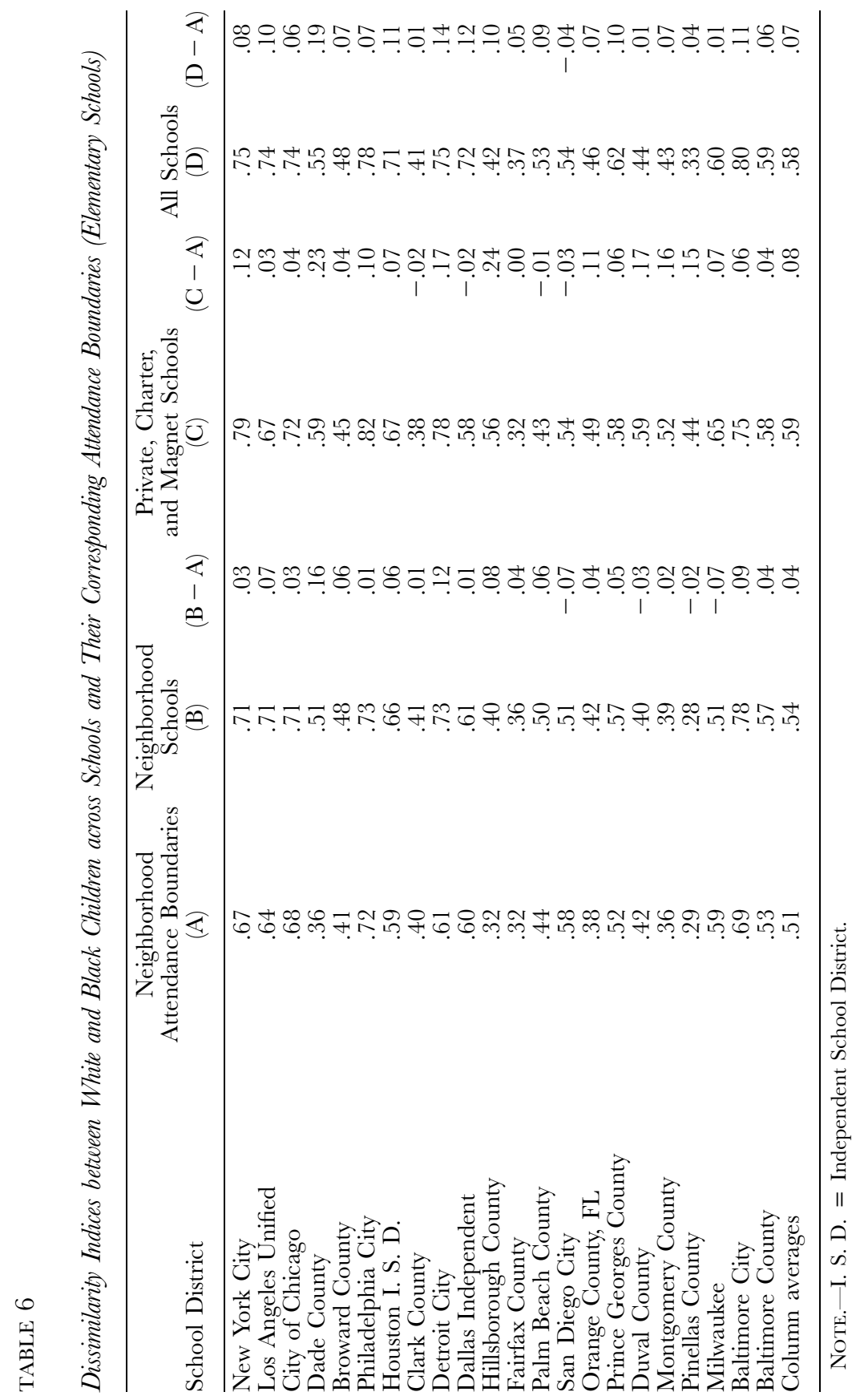

590

This content downloaded from 128.239.241.216 on December 06, 2018 08:11:08 AM 


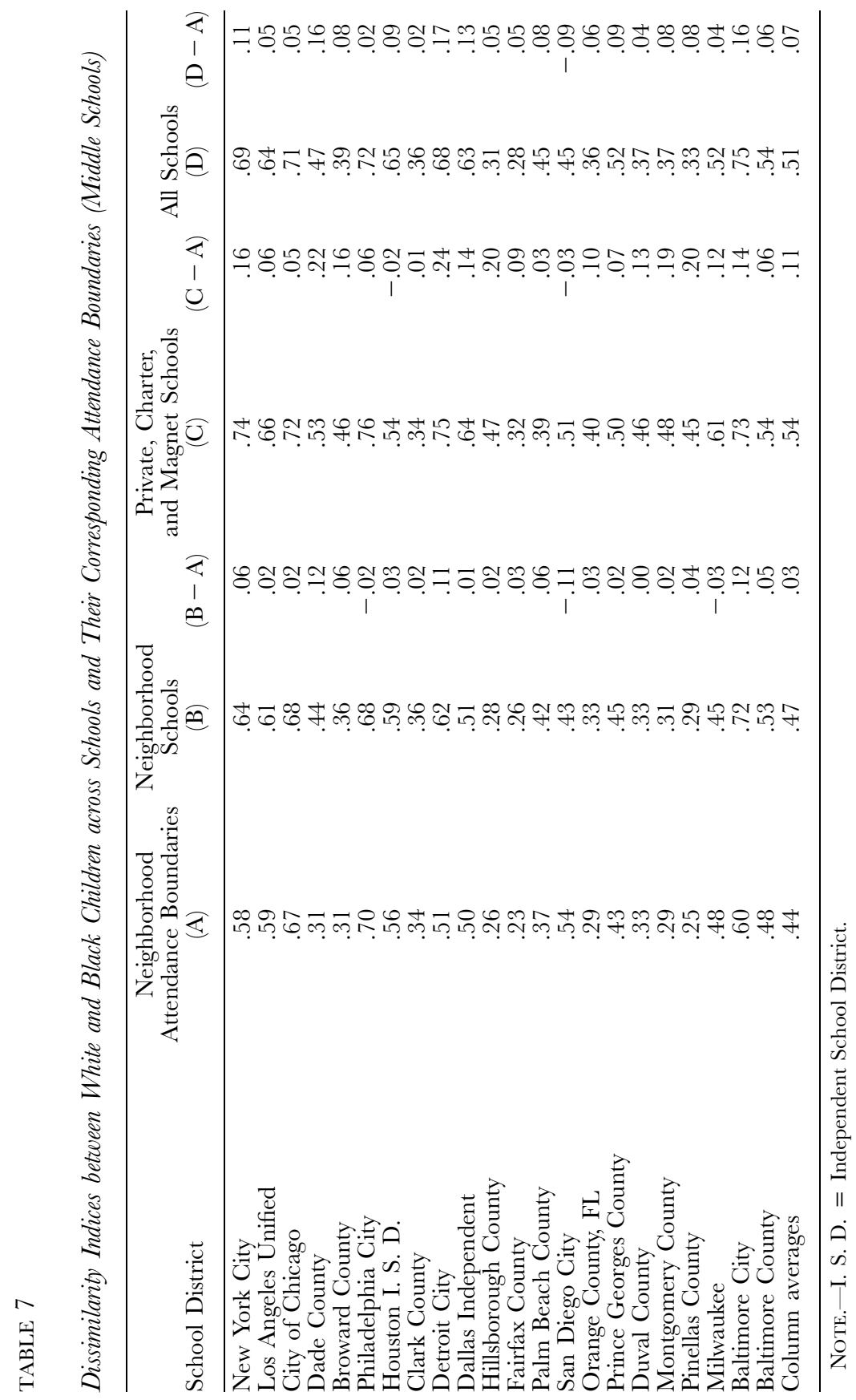

591

This content downloaded from 128.239.241.216 on December 06, 2018 08:11:08 AM 


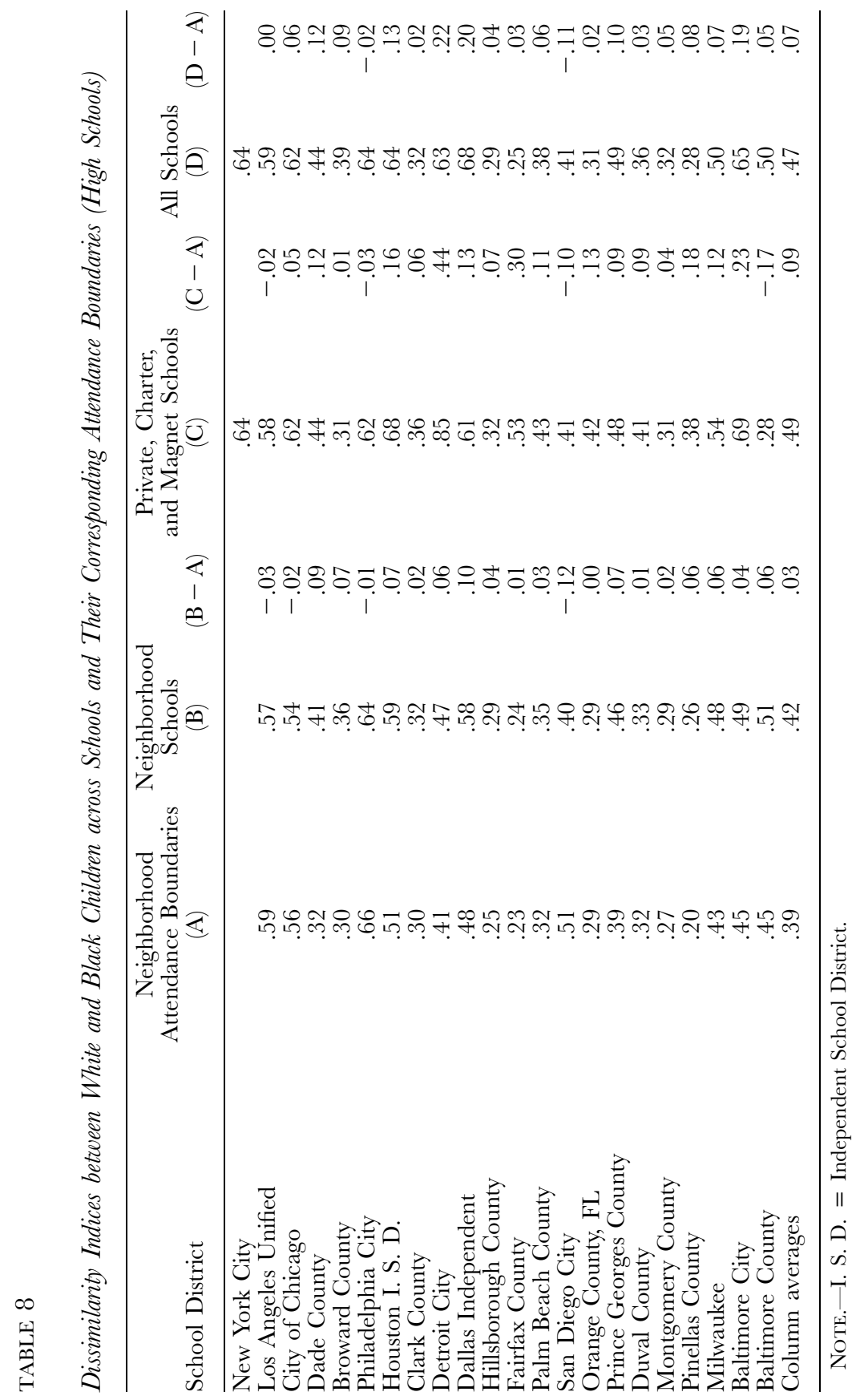

This content downloaded from 128.239.241.216 on December 06, 2018 08:11:08 AM All use subject to University of Chicago Press Terms and Conditions (http://www.journals.uchicago.edu/t-and-c). 


\section{Sohoni and Saporito}

school districts in the United States. We do this by comparing $D$ scores of schools and their corresponding catchment areas between white and nonwhite students.

The results reveal that white/nonwhite $D$ is higher in schools (col. B) than their catchment areas (col. A) at the elementary school level (table 6) and at the middle and high school levels (tables 7 and 8, respectively). At the elementary school level, the results indicate that 18 of the 22 school districts have schools that are more segregated than their corresponding catchment areas. In a handful of school districts this gap is noteworthy. For instance, Baltimore City, Dade County, Detroit City, Hillsborough County, Los Angeles, and Palm Beach County all have dissimilarity scores across schools that are from .07 to .16 points higher than dissimilarity scores in their catchment areas. By contrast, however, white/nonwhite segregation in two school districts (San Diego City and Milwaukee) is considerably lower in schools than their neighborhoods. These districts have programs designed to reduce racial segregation. ${ }^{9}$ Still, the typical school district has greater levels of white/nonwhite segregation in their schools than their neighborhoods. These pattern result from the movement of some students from neighborhood-based schools to private, magnet, and charter schools. Only in those districts that implement a multiracial desegregation plan is this pattern disrupted.

Similar results can be observed at the middle and high school levels (we focus on high schools here for the sake of space). As with elementary schools the majority of districts (18 of 21) have dissimilarity scores that are higher in schools than their corresponding boundaries, and only one of these districts (San Diego City) has considerably lower levels of segregation in schools than their catchment areas. Indeed, the average gap in $D$ between schools and neighborhoods across all high schools is .03 (just about the same as in elementary schools).

We were also interested in observing the impact of private, charter, and magnet schools on overall racial segregation within school districts. To examine this issue, we determine whether racial segregation across all nonneighborhood schools within a district (i.e., private, charter, and magnet schools) was higher than in school attendance boundaries. If it is true that private, charter, and magnet schools are more integrated than public schools, then the overall level of racial segregation within school districts would be reduced. Such a finding would support arguments that schools of choice draw children away from segregated neighborhoods and integrate students in schools of choice by race.

We find no evidence to suggest that schools of choice reduce racial segregation within school districts. In fact, we find just the opposite. When we compare $D$ across all schools within school districts (col. C) with our baseline measure of $D$ across school attendance zones (col. A), we find greater segregation across all schools than attendance boundaries $(\mathrm{C}-\mathrm{A})$ in 18 of the 22

AUGUST 2009 


\section{Mapping School Segregation}

school districts at the elementary school level, 20 of 22 at the middle school level, and all of the high schools. Moreover, the average difference between $D$ in all schools and attendance boundaries is greater than $D$ between neighborhood schools and their attendance boundaries. The average difference is .08 for elementary schools, .11 for middle schools, and .09 for high schools. These results indicate clearly that the availability of nonneighborhood schools exacerbates segregation within school districts because the distribution of white and nonwhite students within them is even less than in school catchment areas.

Finally, we examine the extent to which racial segregation is greater in all schools (i.e., local neighborhood-based public schools and private, charter, and magnet schools) versus segregation based on residential patterns. In tables 6-8, column D shows segregation scores for all schools, and column D-A shows the difference between segregation in all schools and segregation due to residential patterning across school catchment areas. The results confirm earlier results: segregation is .07 points higher in all schools than it is in school catchment areas (at all three school levels). Increased school segregation results from two processes: first, white children exit integrated neighborhood-based public schools at a greater rate than nonwhite children; second, white and nonwhite children are redistributed in private, charter, and magnet schools more unevenly than they are distributed across residential areas (as defined by school catchment areas), further contributing to racial segregation in schools.

\section{Conclusions}

In this article we obtain unique geographic information depicting school attendance boundaries and use GIS to integrate these maps with census data. The GIS technology allows us to develop a robust way to assess whether public schools are more segregated than they would be if private, charter, and magnet schools did not exist. The results allow us to provide empirical insight into an important policy question raised by education scholars: Does the presence of nonneighborhood schools affect racial segregation in public schools? We find that racial segregation in traditional neighborhood-based public schools is greater than segregation across school catchment areas. This results from white children leaving public schools at higher rates than minorities, particularly when school attendance boundaries are racially balanced. These findings are consistent across elementary, middle, and high schools. Moreover, this basic finding is consistent with earlier work on this subject (Saporito and Sohoni 2006). Similar studies have been conducted in countries such as England, Wales, and the Netherlands (Burgess and Wilson 2005; Burgess et al.

\section{American Journal of Education}




\section{Sohoni and Saporito}

2005; Johnson et al. 2006; Karsten et al. 2003; Willms and Echols 1992). For example, Burgess and colleagues (2005) use dissimilarity to measure white/ black segregation across schools and neighborhoods within local education authorities (LEAs) in the United Kingdom. ${ }^{10}$ They find that across schools and neighborhoods within LEAs, "children are more segregated in school than in their neighborhood" (Burgess et al. 2005, 1052). Moreover, most of these studies find greater segregation across schools than residential areas for most ethnic group pairings. For example, there are higher levels of segregation across schools than across neighborhoods between white students and students from the following ethnic groups: Africans, black Caribbeans, Chinese, Indians, and Pakistanis. Findings in these studies are inconsistent with the theoretical discussion of other scholars who suggest that schools of choice may help reduce racial segregation (Brandl 1998; Chubb and Moe 1997; Coleman 1992; Coons and Sugarman 1978; Finn 1990; Greene et al. 1998; Hess and Leal 2001; Hoxby 1998; Merrifield 2001; Wolf et al. 2000).

We find that there are differences in racial segregation between a hypothetical school system in which all children attend local public schools and actual levels of racial segregation in neighborhood-based public schools. Indeed, when we consider the racial distribution of all children in all schoolsincluding public, private, magnet, and charter schools - we find that racial segregation is even higher than across school-based residential areas. This is instructive. If policy makers enact programs that subsidize the school choice options of families (e.g., voucher programs) without taking into account their effects on racial segregation, the increased mobility of students is likely to mirror current race-specific distributions of students in public and private schools. Still, many scholars and policy makers argue that the increased subsidization of school programs could reduce segregation. We argue that such subsidies could only reduce racial segregation if racially disadvantaged children were the target of voucher programs and the choices of poorer white children had race-based restrictions. Given the movement away from race-based integration policies, it seems very unlikely that voucher programs would be allowed to create stringent race-based restrictions either in terms of the racial groups permitted to use vouchers or on the racial composition of schools from which students are allowed to choose. Further, insofar as the recent ruling by the U.S. Supreme Court in Parents Involved in Community Schools v. Seattle School District (551 U.S. 701 [2007]) limits the options districts have for regulating school racial composition, the prospects that school choice can serve the goal of promoting integration have been limited.

Finally, our use of GIS makes it possible explore the issue of geographic scale on integration within schools. Unlike earlier work that bundles elementary, middle, and high schools into a single analysis (Archbald 2004), we disaggregate our data into elementary, middle, and high schools to unpack

AUGUST 2009 


\section{Mapping School Segregation}

the potential changes in segregation across all three levels. We find that as catchment areas expand in geographic coverage as one moves up the grade system, segregation between white and nonwhite children diminishes (from an average $D$ score of .51 in elementary school boundaries to .39 in high school boundaries). This suggests that the issue of segregation (at least as measured by dissimilarity) may be overstated in the literature because much research tends to lump younger children in with older children when examining issues of school inequality.

Despite the decline in segregation with the expansion of school areas, local neighborhood schools are more segregated than their catchment areas, and the difference in segregation between schools and the catchment areas is about the same at all three grade levels. This finding undermines Coleman's contention that white and nonwhite students leave neighborhood schools in about the same proportions (and thus that school choice does not influence racial segregation in public schools). Moreover, the redistribution of children in private, magnet, and charter schools contributes to the segregation of all students even more - indeed, the difference in segregation in students across public school boundaries (due almost exclusively to residential patterning) and all neighborhood, private, magnet, and charter schools is about seven points.

The use of GIS allows educational researchers to expand their ability to answer thorny questions that cannot be addressed with typical ready-made data sets such as the GCD or tabular data from the census. Indeed, in the current study, GIS enables users to link the two data sets to build a unique data set. Further questions related to school segregation and school catchment areas can be explored but, as with the current study, this is only made possible with GIS. Earlier in this article we alluded to the phenomenon of "gerrymandering," a term typically used to describe the drawing of congressional districts to maximize the representation of a political party in a single state (e.g., by concentrating Republicans in a few congressional districts in an effort to create slight majorities of Democrats in the majority of the remaining congressional districts). The same phenomenon may apply to the districting of schools with respect to racial composition - it may be the case that the school boundaries are drawn in such a way that they either maximize or minimize segregation. Geographic information systems can answer this question by redrawing school catchment areas so that they encompass residential areas in such a way as to create optimal minimal and maximal levels of segregation. Using GIS to compare hypothetical maximal and minimal segregation patterns of gerrymandered boundaries with boundaries as drawn currently by school districts will allow scholars of racial segregation to determine how much individual choice for schools and residential areas contributes to segregation and how much is due to the way in which school districts draw their boundaries.

\section{American Journal of Education}


Sohoni and Saporito

Notes

This research was supported by the American Educational Research Association, which receives funds for its AERA Grants Program from the National Science Foundation (under grant REC-0310268) and the U.S. Department of Education's National Center for Educational Statistics. Opinions reflect those of the authors and not of the granting agencies. We are grateful to two students, Charles Adair and Laura Nixon, who helped collect and integrate our data. The authors received helpful comments and suggestions from the anonymous $A \mathcal{F} E$ reviewers.

1. The New York City school district does not have catchment areas for high schools.

2. Existing GIS software allows users to make geographic layers semitransparent so that one can overlay digital images and see all of them simultaneously.

3. We recognize that families may make residential choices that are related to the availability and proximity of private, magnet, or charter schools in a given location. It may be that some families elect to live in a racially or economically integrated public school attendance boundary because some of these neighborhoods provide easy access to high-quality nonneighborhood schools. Thus, for example, if private, charter, and magnet schools were not an option for parents, it is likely that many of these families would change their current residence. Still, our findings suggest that white parents would elect to live in school attendance boundaries with fewer nonwhite children.

4. Importantly, over 99 percent of elementary schools in our study have students enrolled up to the fourth grade, while all middle schools contain a seventh or eighth grade and all high schools have ninth and tenth grades. Including all of the grades covered for each of the elementary, middle, or high schools in our study would have resulted in a wide range of school types. For instance, 5 percent of elementary schools would have ended with grade 4, 57 percent with grade 5, 31 percent with grade 6 , and 8 percent with grade 8 . Counting children only in limited grade ranges limits measurement error associated with changes in the racial composition of younger or older children in lower or higher grades.

5. Of concern is the inclusion of multiracial children (e.g., children whose parents and/or grandparents are of two or more different races) in the 2000 census. Roughly 5 percent of the children in our data are classified as multiracial. This presents a challenge because the GCD assigns every child to a single race. Some children who are classified as multiracial in the census are classified as monoracial in the CCD. Since we cannot systematically assign multiracial children in the 2000 census to a single race because we do not know the racial backgrounds of their parents and/or grandparents, we assume that all multiracial children are nonwhite. This is the most conservative approach, as it underestimates the percentage of children in each school catchment area who classify themselves as white in the Common Core of Data. Still, there are alternative ways to classify multiracial children. For instance, we assigned mixed children to different races based on the racial percentages existing within each census block. If black children were the modal racial group within a block, we assumed that all of the multiracial children in the block were also black. When we constructed racial percentages based on this assignment technique, the results were nearly identical to those presented throughout this article.

6. This figure is based on schools that serve only children living in the catchment area and excludes neighborhood-based specialty schools that draw some children from outside the borders of their attendance boundaries. This allows us to focus strictly on the relationship between schools and their corresponding neighborhoods. In later anal-

AUGUST 2009 


\section{Mapping School Segregation}

yses we include these neighborhood-based specialty schools to describe their impact on racial segregation.

7. The inflection point is calculated using the formula $I=1-b_{1} / 2 b_{2}$, where $I$ is the inflection point and $b_{1}$ and $b_{2}$ are the regression coefficients in the following quadratic equation: $y=a+b_{1} x+b_{2} x^{2}$.

8. Reviewers worried whether the independent variables were so highly correlated that they would make the regression results meaningless. Fortunately, the correlations between the racial variables (i.e., the percentage of white, black, and Hispanic children in a school catchment area) are not collinear.

9. Some districts, such as in Milwaukee, have regional zones that contain several or more schools. Students who live within the region can attend any school within the region (although first preference is given to students who live within a school's neighborhood catchment area). Other districts, such as San Diego City, have specialty programs (e.g., art or science) within neighborhood schools that attract children from across the district (although enrollment preference is given to students who live within a school's catchment area).

10. The neighborhoods in these studies are not the same as school catchment areas.

\section{References}

Alba, Richard D., and John R. Logan. 1993. "Minority Proximity to Whites in Suburbs: An Individual Level Analysis of Segregation." American fournal of Sociology 98: $1388-1427$.

Archbald, Douglas. 2004. "School Choice, Magnet Schools, and the Liberation Model: An Empirical Study." Sociology of Education 77:283-310.

Astin, Alexander. 1992. "Educational 'Choice': Its Appeal May Be Illusory." Sociology of Education 65:255-60.

Brandl, John. 1998. "Governance and Educational Quality.” In Learning from School Choice, ed. Paul Peterson and Bryan Hassel. Washington, DC: Brookings Institution.

Burgess, Simon M., and Deborah Wilson. 2005. "Ethnic Segregation in England's Schools." Transactions of the Institute of British Geographers 30:20-36.

Burgess, Simon M., Deborah Wilson, and Ruth Lupton. 2005. "Parallel Lives? Ethnic Segregation in Schools and Neighborhoods." Urban Studies 42:1027-56.

Chubb, John E., and Terry M. Moe. 1997. "Politics, Markets and Equality in Schools." In Autonomy and Choice in Context, ed. Rina Shapira and Peter Cookson. New York: Elsevier Science.

Clotfelter, Charles T. 2004. "Private Schools, Segregation, and the Southern States." Peabodv Fournal of Education 79:74-97.

Coleman, James S. 1992. "Some Points on Choice in Education (in Exchange)." Sociology of Education 65:260-62.

Coleman, James S., and Thomas Hoffer. 1983. "Response to Taeuber-James, CainGoldberger, and Morgan." Sociology of Education 56:219-34.

Coleman, James S., Thomas Hoffer, and Sally Kilgore. 1982a. "Achievement and Segregation in Secondary Schools: A Further Look at Public and Private School Differences." Sociology of Education 55:162-82.

Coleman, James S., Thomas Hoffer, and Sally Kilgore. 1982b. "Cognitive Outcomes in Public and Private Schools." Sociology of Education 55:65-76.

Coons, John E., and Stephen D. Sugarman. 1978. Education by Choice: The Case for Family Control. Berkeley: University of California Press.

\section{American Journal of Education}




\section{Sohoni and Saporito}

Crowder, Kyle D. 2000. "The Racial Context of White Mobility: An Individual-Level Assessment of the White Flight Hypothesis." Social Science Research 29:223-57.

Emerson, Michael O., George Yancey, and Karen Chai. 2001. "Does Race Matter in Residential Segregation? Exploring the Preferences of White Americans." American Sociological Review 66:922-35.

Finn, Chester E. 1990. "Why We Need Choice." In Choice in Education, ed. William L. Boyd and Herbert J. Walberg. Berkeley: McCutchan.

Greene, Jay P., William G. Howell, and Paul E. Peterson. 1998. "Lessons from the Cleveland Scholarship Program." In Learning from School Choice, ed. Paul Peterson and Bryan Hassel. Washington, DC: Brookings Institution.

Hallinger, Philip, and Joseph Murphy. 1985. "Characteristics of Highly Effective Elementary School Reading Programs." Educational Leadership 42:39-42.

Henig, Jeffrey R. 1996. "The Local Dynamics of Choice: Ethnic Preferences and Institutional Responses." In Who Chooses? Who Loses? Culture, Institutions and the Unequal Effects of School Choice, ed. Bruce Fuller and Richard Elmore. New York: Teachers College Press.

Hess, Frederick M., and David L. Leal. 2001. "Quality, Race, and the Urban Education Marketplace." Urban Affairs Review 37:249-66.

Hoxby, Caroline M. 1998. "Analyzing School Choice Reforms That Use America's Traditional Forms of Parental Choice." In Learning from School Choice, ed. Paul Peterson and Bryan Hassel. Washington, DC: Brookings Institution.

Johnson, Ron, Simon Burgess, Deborah Wilson, and Richard Harris. 2006. "School and Residential Ethnic Segregation: An Analysis of Variations across England's Local Education Authorities." Regional Studies 40:973-90.

Karsten, Sjoerd, Guuske Ledoux, Jaap Roeleveld, Charles Felix, and Dorothé Elshof. 2003. "School Choice and Ethnic Segregation." Educational Policy 17:452-77.

Lankford, Hamilton, and James Wyckoff. 2001. "Who Would Be Left Behind by Enhanced Private School Choice?" Zournal of Urban Economics 50:288-312.

Lankford, Hamilton, and James Wyckoff. 2006. "The Effect of School Choice on Residential Location and the Racial Segregation of Students." In Improving School Accountability: Check-Ups or Choice, vol. 14 of Advances in Applied Microeconomics, ed. Timothy Gronberg and Dennis Jansen. Oxford: Elsevier.

Massey, Douglas S., and Nancy A. Denton. 1993. American Apartheid. Cambridge, MA: Harvard University Press.

Merrifield, John. 2001. The School Choice Wars. Lanham, MD: Scarecrow Education.

National Center for Educational Statistics. 2000a. Common Core of Data (CCD). School years 1990-2000 through 2002-2003. Washington, DC: U.S. Department of Education.

National Center for Educational Statistics. 2000b. 1999 Private School Survey (PSS). Washington, DC: U.S. Department of Education.

National Center for Educational Statistics. 2000c. School District Data Book (SDDB). Washington, DC: U.S. Department of Education.

Purkey, Stewart C., and Marshall S. Smith. 1983. "Effective Schools: A Review." Elementary School fournal 83:427-52.

Quillian, Lincoln. 1999. "Migration Patterns and the Growth of High-Poverty Neighborhoods, 1970-1990." American fournal of Sociology 105:1-37.

Quillian, Lincoln. 2002. "Why Is Black-White Residential Segregation So Persistent? Evidence on Three Theories from Migration Data." Social Science Research 31:197-229.

Reardon, Sean F., and John T. Yun. 2002. "Private School Racial Enrollments and Segregation.” Report, The Civil Rights Project, Harvard University, Cambridge, MA

AUGUST 2009 


\section{Mapping School Segregation}

Saporito, Salvatore J. 2003. "Private Choices, Public Consequences: Magnet School Choice and Segregation by Race and Poverty." Social Problems 50:181-203.

Saporito, Salvatore J., and Deenesh S. Sohoni. 2006. "Coloring Outside the Lines: Racial Segregation in Public Schools and Their Attendance Boundaries." Sociology of Education 79 (2): 81-105.

Saporito, Salvatore J., and Deenesh S. Sohoni. 2007. "Mapping Educational Inequality: Concentrations of Poverty among Poor and Minority Students in Public Schools." Social Forces 85 (3): 1227-54.

South, Scott J., and Kyle D. Crowder. 1998. "Leaving the 'Hood': Residential Mobility between Black, White, and Integrated Neighborhoods." American Sociological Review 63:17-26.

Taeuber, Karl E., and David R. James. 1982. "Racial Segregation among Public and Private Schools." Sociology of Education 55:133-43.

Taeuber, Karl E., and David R. James. 1983. "Racial Segregation among Public and Private Schools: A Response." Sociology of Education 56:204-7.

U.S. Bureau of the Census. 2003. Summary File 1, Census of Population and Housing. Washington, DC: U.S. Government Printing Office.

Wells, Amy Stuart, and Robert L. Crain. 1992. "Do Parents Choose School Quality or School Status: A Sociological Theory of Free Market Education." In The Choice Controversy, ed. Peter W. Cookson Jr. Newbury Park, CA: Corwin.

Willms, Douglas, and Frank Echols. 1992. "Alert and Inert Clients: The Scottish Experience of Parental Choice of Schools." Economic of Education Review 11:339-50.

Wolf, Patrick J., William G. Howell, and Paul E. Peterson. 2000. "School Choice in Washington, DC: An Evaluation after One Year." In The Conference on Vouchers, Charters and Public Education. Program on Education Policy and Governance. Cambridge, MA: Harvard University Press.

Wrinkle, Robert D., Joseph Steward, and J. L. Polinard. 1999. "Public School Quality, Private Schools and Race." American Fournal of Political Science 43:1248-53.

600 American Journal of Education 